\title{
Educação ambiental e destino dos resíduos em Gijón/Espanha
}

\author{
Envronmental education and destination of waste in Gijon/Spain
}

\author{
Darlize Déglan Borges Beulck Bender ${ }^{1}$ \\ ${ }^{1}$ Graduada em Ciências Biológicas pela Universidade da Região da Campanha - URCAMP, Campus Alegrete, RS/Brasil
}

\section{RESUMO}

Atualmente o mundo tem presenciado e se preocupado mais com os problemas decorrentes do mau uso dos recursos naturais e do destino dos resíduos procedentes da urbanização. Em função disto, iniciativas que desenvolvam a educação ambiental tornam-se vitais para um meio ambiente melhor. Este estudo tem como objetivo mostrar as formas de ensinar educação ambiental e o destino dos resíduos sólidos urbanos na Espanha, mais especificamente na cidade de Gijón. Tem como metodologia pesquisas locais, descritivas e exploratórias, e os resultados obtidos ratificam que a principal ação na conservação, preservação e na sustentabilidade da cidade são os programas de educação ambiental. O Governo usa métodos adequados e contextualizados com a realidade local e a complexidade dos problemas ambientais. Por fim, constata-se que a educação ambiental é uma relevante estratégia de mudança para obter uma cidade conservada e, por que não, um planeta conservado, que possa proporcionar mais qualidade de vida aos seus habitantes.

Palavras-chave: Educação Ambiental. Meio Ambiente. Resíduos Sólidos Urbanos.

\begin{abstract}
Currently the world has been more concerned with the problems arising from the misuse of natural resources and the destination of the wastes from urbanization. Consequently, initiatives to develop envronmental education become vital to better management of the nature. The objective of this study is shows the ways of teaching envronmental education and the destiny solid waste urban in Spain, specifically in the city of Gijón. The methodology is based on local researches, descriptive and exploratory. The obtained results confirm that the main action in the conservation, preservation and sustainability are the programs for envronmental education because it shows the awareness of the people and of the Government with respect to the envronment, by using appropriate methods, contextualized to local reality and the complexity that are the envronmental problems. As result, it appears that envronmental education is an important strategy for change and to have a preserved city, which can provide better quality of life for the population.
\end{abstract}

Keywords: Envronmental Education. Envronment. Solid Urban Waste. 


\section{Introdução}

Através da educação ambiental ocorre a sensibilização do indivíduo, e possível, conscientização, que levam a mudanças significativas a curto e longo prazos.

Quando iniciada nos primeiros anos de vida, ainda em casa, as crianças aprendem, principalmente com o exemplo dos pais, como agir agora e posteriormente. Depois, na escola, a mesma faz parte do dia-a-dia das crianças, adolescentes e jovens, nas diversas disciplinas e conteúdos, também através da convivência com os professores, diretores e demais funcionários da escola.

Portanto, a educação ambiental deve ser inserida em todos os níveis de ensino, para que, futuramente, tenham-se pessoas conscientes e preocupadas com a importância de viver em um meio ambiente ecologicamente equilibrado. Através disso, acredita-se que a educação ambiental é uma, ou até mesmo, a única estratégia para uma mudança relevante.

A justificativa de ensinar a educação ambiental na Espanha baseia-se em leis e planos, tais como a Lei 10/1988, que tem como principal objetivo a prevenção da produção e redução de resíduos, juntamente com a proposta da reciclagem, com a finalidade de proteger o meio ambiente e a saúde das pessoas; e os planos nacionais de resíduos cujo principal objetivo é complementar a nova Lei de Resíduos.

Assim, observa-se que o governo cria os planos com objetivos específicos de redução, reutilização, reciclagem, recuperação e outras formas de ações para atingir os objetivos de melhoria da saúde da população e descarte de lixo.

\section{Metodologia}

Com objetivo de conhecer e compreender as características da cidade onde desenvolveu-se a pesquisa, primeiramente foi necessária uma pesquisa exploratória, descritiva e investigativa da cidade de Gijón, localizada no Estado de Astúrias na Espanha.

Observou-se as características socioambientais, a história e as políticas do Consórcio para a Gestão dos Resíduos Sólidos de Astúrias - COGERSA, através do método dedutivo, por meio de observação direta e indireta, onde foram desenvolvidos os objetivos do presente estudo.

A pesquisa realizada é classificada como exploratória, descritiva e explicativa. Isto porque primeiramente foi preciso fazer um levantamento da cidade de Gijón, através de revisões bibliográficas e documentais para se ter conhecimento dos programas oferecidos e realizados através da prefeitura local.

Após essa exploração de dados e, posterior descrição e explicação de objetivos e metas, pôde-se obter um entendimento maior a respeito dessas iniciativas e consequências no cotidiano da população com respeito a preservação do meio ambiente.

Quanto à metodologia, a presente pesquisa sucedeu através do método dedutivo. Esta opção se justifica porque o método escolhido permite organizar e especificar o 
conhecimento já consolidado das consequências positivas da educação ambiental, partindo de um ponto evidente, já estabelecido em outras partes do mundo, como forma de conscientização, melhoria da qualidade de vida e destino dos resíduos sólidos urbanos.

Esta pesquisa foi realizada por meio de observação direta e indireta.

Direta porque a coleta de dados e informações foi elaborada através de visita a sede da COGERSA e, acompanhamento das aulas de Engenharia Química Industrial, da Universidade de Oviedo - UNIOVI - Campus Gijón, na disciplina de Tratamento e Reciclagem de Resíduos Sólidos e Solos.

Indiretamente, através de pesquisas bibliográficas e documentais quanto aos projetos de educação ambiental realizados localmente incluindo o destino e tratamento dos resíduos sólidos urbanos através da COGERSA.

Utilizou-se da elaboração de um plano de trabalho realista, baseando-se nas principais ideias observadas, o problema da pesquisa, os objetivos e hipóteses já descritos anteriormente.

Estas ferramentas permitiram mostrar os métodos de ensino da Educação Ambiental implementados para os estudantes, adultos, cadeirantes e comerciantes de Gijón; entender como é a coleta seletiva e destinação dos resíduos através da COGERSA; e, expor os resultados práticos da organização e preocupação local para com o destino dos resíduos sólidos urbanos gerados.

O material documentado, bem como, as respectivas análises foram organizadas em um relatório de pesquisa.

\section{Educação Ambiental e destino dos resíduos na Espanha.}

A expansão da educação ambiental na Espanha coincidiu com a mudança diplomática, a formação de novas associações ambientais e, nas escolas, com o ensino sobre o meio ambiente. Desde o século XIX, as empresas, cooperativas e grupos também foram os pioneiros no desenvolvimento da visão ambiental no país. A década de 80 foi marcada por alguns eventos na área ambiental, principalmente para avaliar os sistemas, leis e decretos nessa área e começar as Conferências de Educação Ambiental.

Nos anos 90, já existiam critérios de qualidade nos programas e atividades realizadas com a população para mostrar os princípios da sustentabilidade a toda a sociedade, pois acredita-se que a educação ambiental seja uma das ferramentas, e não a única ferramenta. Também, nessa década, foi elaborado o "Libro Blanco", Livro Branco, com a finalidade de impulsionar a educação ambiental na Espanha.

Atualmente, nota-se importantes avanços na área ambiental da Espanha. Desde a União Europeia até a organização local traçam sistemas de ensino aos cidadãos através de programas e iniciativas para obter um crescimento notável da conscientização. Através de literaturas e contação de histórias para crianças até programas de separação de resíduos entre os comerciantes e lares. Além do setor público, muitas empresas privadas, fora do 
âmbito educacional, incorporam-se ao desenvolvimento de tecnologias, equipamentos e materiais para ajudar nesse desenvolvimento sustentável.

Toda a Gestão de Resíduos da Espanha é realizada pela União Europeia, onde todos os estados devem seguir suas legislações e diretivas firmadas.

Na Espanha há um Sistema Integrado de Gestão - SIG, que interliga várias empresas e fábricas, com a intenção de manter o ciclo dos resíduos, por exemplo: consumo, separação, coleta, reciclagem, empresa, consumo. Assim, as principais empresas que possuem uma gestão completa dos resíduos na Espanha são: a Ecoembes, a Ecovidrio e a Ecopila.

As principais funções da SIG são: criação e funcionamento do sistema de coleta e reciclagem das pilhas e baterias usadas, independente das marcas; a contratação dos agentes econômicos que participam no processo da gestão sob a responsabilidade de todos; a otimização dos custos de coleta, reciclagem, administração e comunicação; troca de experiências com outros SIGs Europeias de pilhas (ECOPILA, 2014).

Atualmente, a Espanha está entre os dez países da Europa que mais reciclam resíduos (ECOEMBES, 2013).

\subsection{Educação Ambiental e destino dos resíduos em Gijón/Espanha}

Gijón é administrada, no que se refere ao meio ambiente, pela Empresa Municipal de Serviços de Meio Ambiente de Gijón S.A. - EMULSA, a qual, em novembro de 1978, começou a prestar seus serviços através da gestão de coleta domiciliar de resíduos.

Nos anos 80, o governo asturiano, juntamente com oito prefeituras, planejou realizar a gestão dos resíduos sólidos urbanos para todo o estado, criando então a COGERSA, tornando-se assim o pioneiro na Espanha e servindo de modelo para outras comunidades.

A COGERSA foi formada para dar uma solução centralizada ao problema dos resíduos em Astúrias, mostrando as soluções mais adequadas e rápidas para as necessidades da população local.

Juntamente com a gestão dos resíduos residenciais, comerciais e hospitalares, a COGERSA também realiza a educação ambiental com crianças, jovens, adultos e idosos, através de diversas iniciativas e atividades práticas nas residências, escolas, locais de trabalho e ambientes públicos.

Atualmente a COGERSA tem a capacidade de tratar os resíduos que são produzidos em vários setores, tais como indústrias, construção e demolição, rede de saúde e hospitalar, entre outros.

Conta com um Plano de Futuro, na qual estabelece as estratégias a serem seguidas para continuar garantindo, pelo menos a médio prazo, um modelo de gestão de resíduos eficiente, moderno e que respeite o meio ambiente. Este plano foi aprovado em 2003 juntamente com o Governo de Astúrias e representantes das 78 prefeituras do estado. 


\subsection{A educação ambiental utilizada pela EMULSA.}

Através da Lei 10/1998 e os Planos Nacionais, a EMULSA, formulou planos regionais com objetivos específicos de redução, reutilização, reciclagem, recuperação e outras formas de descartes para atingir os objetivos de melhoria da saúde da população e descarte de lixo.

Atualmente a EMULSA divide suas ações em cinco áreas: higiene urbana, resíduos sólidos urbanos, limpeza de escolas e edifícios públicos, manutenção e limpeza das zonas verdes (jardins, parques, etc.) e sinais de trânsito.

Junto com o trabalho de limpeza e destinação dos resíduos sólidos urbanos, geralmente, realizam a contação de histórias para crianças, cursos sobre educação ambiental para estudantes (visitas aos pontos limpos, reciclagem, elaboração de hortas nas escolas), concursos para a produção e exibição de projetos de artes com reciclagem, entre outros.

Através dessas ações pode-se sensibilizar o cidadão a desempenhar mudanças significativas dos seus atos errôneos que prejudicam o meio ambiente.

A EMULSA acredita que a educação ambiental deve ser inserida em todos os níveis de ensino, para que futuramente tenham-se pessoas conscientes e preocupadas com a importância de viver em um meio ambiente ecologicamente equilibrado.

\subsubsection{Educação Ambiental com crianças e estudantes}

No que se refere a educação ambiental com crianças e adolescentes pode-se afirmar que quanto mais a criança ouve histórias, mais ela aprende e os conflitos cognitivos são despertados e resolvidos, ajudando-a no entendimento e aprendizado. Dessa forma, quanto mais a criança for incentivada a resolver as situações do dia-a-dia, melhor será quando chegar à idade adulta (PATELLI, 2014).

A EMULSA realiza a educação ambiental com crianças, a partir de 3 anos de idade, nos maternais. No último ano utilizou-se de workshop com o tema "começar pequeno", onde realizou atividades durante a Campanha de Sensibilização Ambiental, distribuídos por quatorze escolas maternais de Gijón.

Essa atividade teve como principal objetivo criar nas crianças a capacidade de diferenciar os tipos de resíduos.

Além deste grande projeto, realizado uma vez ao ano, desde 2012, a EMULSA realiza outras frentes de trabalho com os estudantes. Nove escolas participaram do I Concurso Escolar “Gijón, capital da reciclagem”, entre junho de 2012 e junho de 2013.

Cada uma das escolas pôde participar com uma obra (mural, escultura, colagem, etc.) apresentando elementos exclusivos da cidade, através dos resíduos (EMULSA, 2013). As obras foram expostas em alguns espaços públicos, como mostra a Figura 1. 


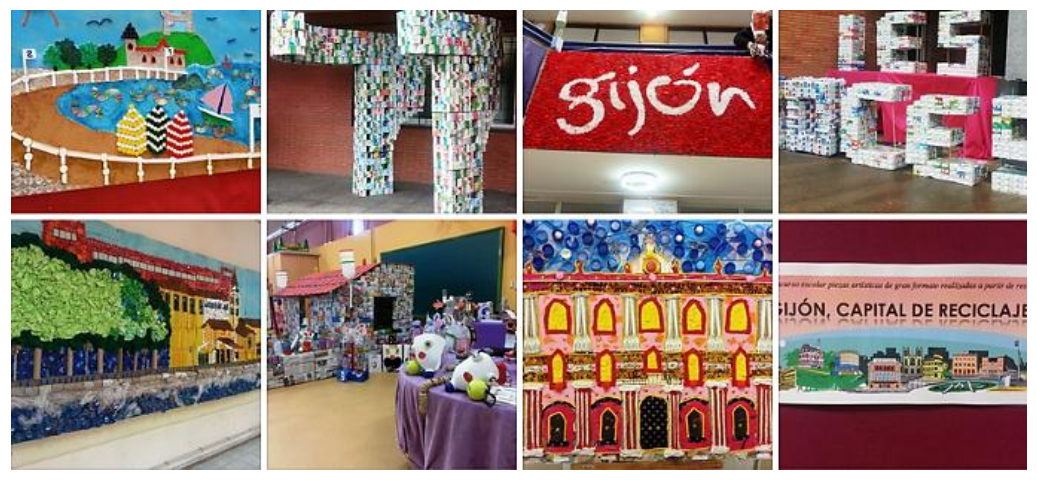

Figura 1 - I Concurso Escolar: Gijón, capital da reciclagem.

Fonte: EMULSA, 2013.

O Objetivo desse concurso foi transmitir a população gijonesa a importância de manter as áreas verdes limpas (parques, praias, etc.), promovendo a reciclagem redução de resíduos e cuidados com o meio ambiente.

A segunda edição do concurso escolar 'Gijón capital de reciclagem", realizada em 2014, teve dezessete finalistas com projetos apresentados por centros de educação primária e secundária da cidade.

As campanhas educacionais incluem a distribuição de material de informação em diferentes mídias e conteúdo para melhorar o conhecimento dos serviços públicos prestados pela Companhia. (EMULSA, 2013).

Mais de 4.000 alunos do ensino pré-escolar, primário e escolas de bacharelado em Gijón já se inscreveram no curso 2014-2015, em nove atividades oferecidas no âmbito da Oferta Municipal de Educação de Gijón.

Dentre as oficinas tem-se: a observação de pássaros no Parque Isabel La Católica, visitas a centros de reciclagem com jogos, oficinas em escolas, jogos nos parques, e conscientização sobre a limpeza ou reciclagem.

Além destes concursos, há a construção de árvores natalinas recicladas, conforme a Figura 2, atividade que é realizada todos os anos, desde 2012, nas escolas municipais da cidade.

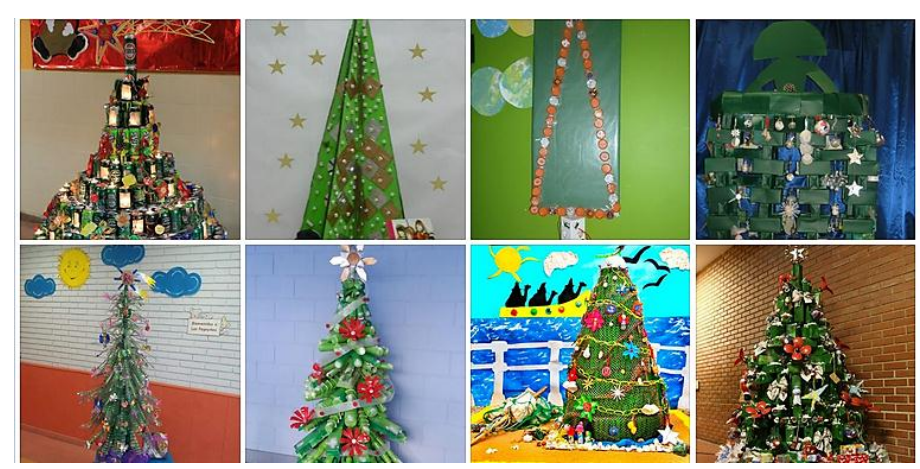

Figura 2 - Concurso de árvores de Natal recicladas em Colégios de Gijón. Fonte: EMULSA, 2014. 
Em 2014 a EMULSA também colaborou com a organização de quatro corridas de bicicletas, uma em cada domingo pelos bairros da cidade.

A "Misión 30 Días en Bici - Gijón", "Missão 30 Dias em Bicicleta - Gijón”, foi realizada com o objetivo de promover o uso diário e cotidiano da bicicleta para melhorar a saúde, bem-estar pessoal e a qualidade de vida.

Este projeto começou na cidade de Minnesota nos Estados Unidos em 2010, com o nome de "30 Days of Biking", e foi difundindo-se para todos os estados do país. Em 2013 teve participação de outros países no mundo, entre eles a Espanha, em que fez parte da Campanha de Conscientização Cidadã Ambiental 2013-2014 em Gijón.

\subsubsection{Educação Ambiental com a população adulta e comerciantes}

Assim como há vários projetos desenvolvidos com os estudantes, também há os que são voltados para o público adulto.

Em 2013 a cidade recebeu o reconhecimento da Associação Internacional de Resíduos Sólidos - ISWA, que lhe concedeu o terceiro prêmio europeu entre os 48 projetos apresentados de 27 países participantes.

A ISWA é uma associação sem fins lucrativos com o propósito de promover a gestão dos resíduos a nível internacional de forma sustentável e através de princípios científicos, econômicos e sociais.

A EMULSA realizou a campanha “¿Sabias que...?", desenvolvida em 2012 e 2013, a fim de aumentar o conhecimento sobre os diferentes aspectos da reciclagem, limpeza de ruas, a gestão de resíduos e a importância das áreas verdes da cidade.

Foram desenvolvidas vinte e cinco ações que incluíam: oficinas de capacitação para crianças e adultos, atuação do marketing cidadão, concursos e exposições de arte reciclada. Cerca de 18.000 pessoas estavam diretamente envolvidas em qualquer uma das ações, que também tiveram muito impacto através das campanhas publicitárias nos meios de comunicação.

Mais algumas ações foram realizadas pela EMULSA durante esse projeto, tais como, "O outono da reciclagem", com oito obras de arte, produzidas por artistas de Astúrias, feitas com materiais recicláveis e instalados nas ruas de Gijón por duas semanas; O flash mob "mares e praias limpas" teve como objetivo apoiar a distribuição de cinzeiros pelas praias; ações destinadas a 2.000 donos de restaurantes e varejistas para aumentar a coleta de vidros e caixas de papelão; participação no convite para a "Semana Europeia da Prevenção de Resíduos", com mercados e oficinas nas escolas; e por fim, o Passeio Canino de San Silvestre.

Além dessas ações, ocorreu também a Campanha de Conscientização Cidadã Ambiental que incluiu ações nas ruas como "Flores por chicletes"; oficinas para jovens e crianças com a reutilização de roupas; oficinas de jardinagem; concurso de jardinagem em varandas, terraços e fachadas (EMULSA, 2013). 
Outro ato ecológico é a Semana Europeia de Prevenção dos Resíduos, que é realizada desde 2009, com o apoio do programa LIFE da Comissão Europeia. Este projeto demonstra o que é preservação, reutilização e reciclagem de resíduos e evidencia os impactos causados ao meio ambiente e a luta contra a mudança climática.

Geralmente esse projeto dura uma semana e tem a coordenação das ações e sensibilizações organizadas pelas administrações públicas, redes associadas, escolas, universidades, empresas, ONG's, etc., que recolhem as doações de roupas e calçados usados.

Outro projeto importante é o Ponto Limpo Móvel, com a campanha "51 razões para reciclar. " Um veículo da COGERSA recorre dezenove zonas rurais asturianas a fim de buscar para dar destinação correta materiais tóxicos e contaminantes, como os presentes em lâmpadas fluorescentes, tintas, etc.

A COGERSA disponibiliza esse serviço gratuitamente com o objetivo de facilitar a participação na reciclagem dos resíduos e coibir a dispersão de lixo incontrolado. $O$ caminhão, Figura 3, realiza o trabalho uma vez ao mês nas zonas rurais.

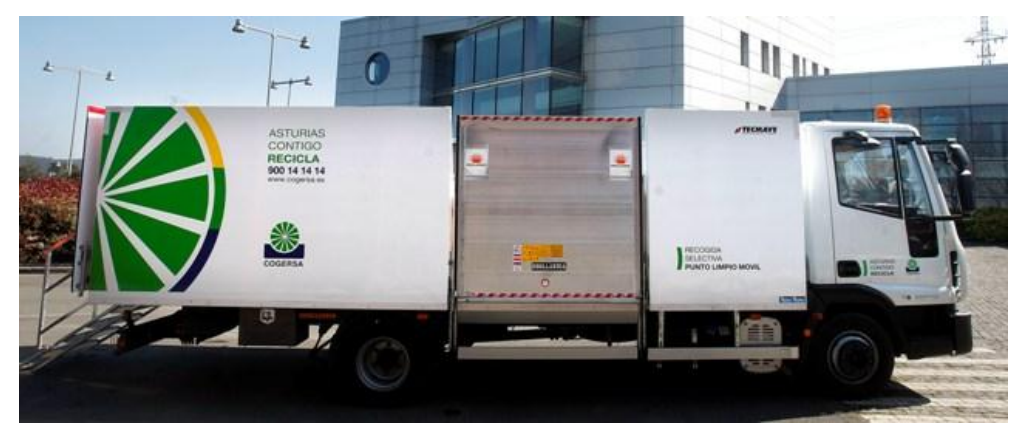

Figura 3 - Ponto limpo móvel.

Fonte: COGERSA, 2014.

O caminhão está equipado com containers internos para a classificação e transporte dos resíduos especiais, como: lâmpadas fluorescentes, lâmpadas LED, pilhas, baterias, discos e DVD's, cartuchos de tinta de impressoras e fotocopiadoras, livros, roupas e calçados, aerossóis, solventes, óleo de cozinha, equipamentos de telefonia e eletrodomésticos (EUROPA PRESS, 2014).

Além das atividades já citadas, também há o projeto Finais de Semana Verdes, onde a população pode visitar as instalações da COGERSA.

Durante esta atividade, com guia, os cidadãos visitam o museu Centro de Interpretação dos Resíduos; conhecem as instalações da COGERSA, com mostra de plantas classificadas; exibição de falcões adestrados para o controle da avefauna, conforme a Figura 4 (a); cursos de reciclagem como mostra a Figura 4 (b); teatro; jogos de reciclagem; e, outras atividades que surgem ao longo dos meses. 


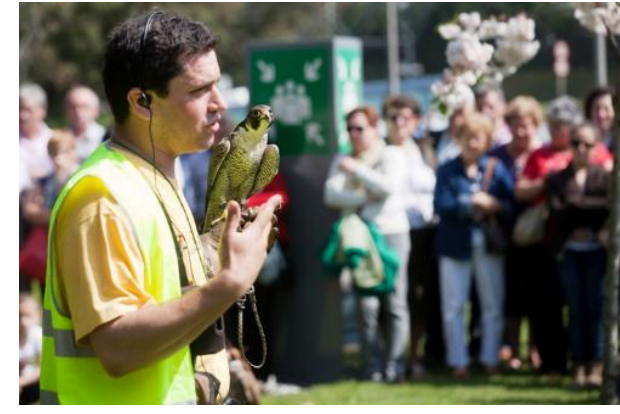

(a)

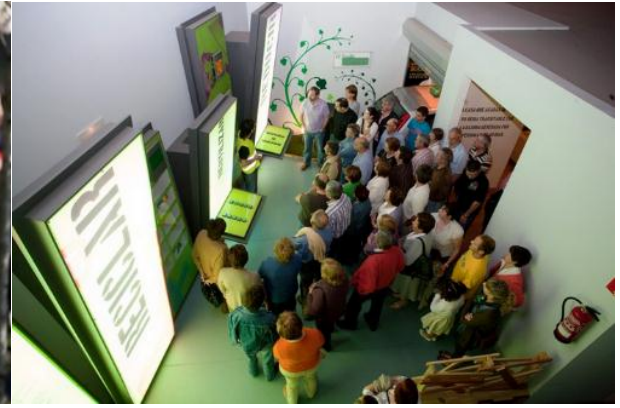

(b)

Figura 4 - Fototeca do Final de Semana Verde.

Fonte: COGERSA, 2014.

\subsubsection{Educação Ambiental com os cadeirantes.}

O Conselho de Administração da EMULSA aprovou no mês de dezembro de 2010, a licitação da compra de 180 containers metálicos, de resíduos sólidos, acessíveis também para cadeirantes, como os mostrados na Figura 5.

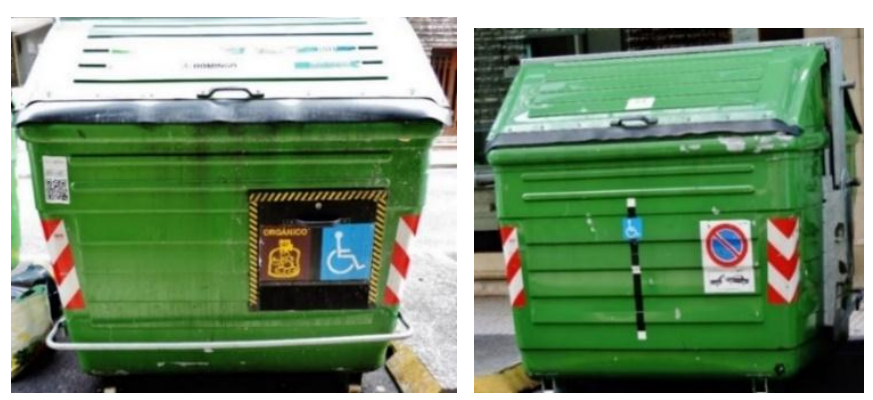

Figura 5 - Containers verdes para a coleta de orgânicos com acesso à cadeirante.

Na área ambiental a EMULSA pretende manter o alto nível de limpeza nas partes turísticas de Gijón; incluir ações e campanhas específicas para melhorar a seleção de resíduos orgânicos e pontos limpos; dentre outras melhorias (EMULSA, 2014).

\section{As práticas ambientais nas ruas de Gijón/Espanha.}

Os gijoneses têm diversos acessos para a separação dos resíduos, tais como, os quatro Pontos Limpos, os Pontos Limpos Móveis (resíduos domésticos perigosos) e, os containers amarelo, verde claro, vermelho, verde escuro, marrom e azul.

\subsection{Resíduos Orgânicos em Gijón.}

De acordo com o informe anual da EMULSA, cerca de 75,53\% de todo resíduo urbano produzido em Gijón é constituído de matéria orgânica. Os principais resíduos domésticos 
separados para a coletas seletivas são os óleos de cozinha, os restos de alimentos e as sobras de frutas e legumes.

Os óleos de cozinha são coletados nos supermercados e Pontos Limpos e, os restos alimentares são coletados em containers verde escuros e marrons.

Em 2014 foram recolhidos cerca de 109.543 litros de óleo de cozinha usado e, em 2013, recolhidos aproximadamente 17.000 toneladas de outros resíduos da cozinha.

Atualmente Gijón conta com 3.750 containers de reciclagem, onde 288 são subterrâneos (soterrados) e 3.462 são containers de resíduos orgânicos.

\subsection{1 Óleos de cozinha}

O recolhimento de óleo usado iniciou em novembro de 2010, onde a EMULSA implantou o serviço de coleta com pontos próprios para a campanha.

No ano de 2012 a COGERSA recolheu, dos pontos limpos, cerca de 7.645 litros de óleo de cozinha usado. Em 2013 ouve um aumento de 10,9\% dessa coleta, chegando a 8.481 litros.

Atualmente são 49 pontos de coleta com aproximadamente 150.000 litros de óleo recolhidos. No primeiro semestre de 2014 foram recolhidos 30.000 litros de óleos usados, superando a quantidade recolhida no primeiro semestre de 2013.

Os óleos recolhidos dos pontos comerciais somaram em 2012 cerca de 2.984 litros, enquanto que em 2013 teve uma recaída de 17,09\%, chegando a 2.474 litros, conforme relatório anual da EMULSA (EMULSA, 2014).

O gestor responsável e autorizado em todos os pontos da cidade é o Pumariega Gestión, que após recolher os óleos dos containers, os leva até a sede Bionor Berantevilla, para a filtração e decantação. Posteriormente este óleo é transportado até a empresa Bionorte e transformado em biodiesel utilizado como combustível nos caminhões da EMULSA.

\subsubsection{Resíduos Alimentares}

Segundo dados da Comissão Europeia, a cada ano são produzidos cerca de 89 milhões de resíduos alimentares nos estados da Europa, mais ou menos, 179 kg por habitante.

Se continuar nesse ritmo, destaca a EMULSA, até 2020 produzirá 126 milhões de toneladas de resíduos alimentares, um aumento de $40 \%$. Os resíduos alimentares são armazenados temporariamente nos containers de cor verde escuro e marrom (EMULSA, 2014).

Atualmente todos os resíduos recolhidos dos containers verde-escuros e marrons são levados até o aterro sanitário, cumprindo o Decreto Real 1481/2011, de 27 de dezembro. O gás natural produzido no aterro sanitário é controlado e é usado, posteriormente, como biogás. 
A COGERSA possui centros de aproveitamento do biogás, da qual possuem nove geradores de eletricidade com potência total instalada de 1,87GW/. Além disso a rede possui duas tochas que eliminam o excesso de biogás produzido (COGERSA, 2014).

Atualmente a área do aterro é de 70 hectares, com volume total de $18.000 .000 \mathrm{~m}^{3}$. Possui 180 linhas de captação de biogás que partem de mais de 330 poços, com três centrais de regulação de todo o processo de captação do biogás na sede da COGERSA.

Ainda tratando-se de resíduos orgânicos, a população também é incentivada a realizar a compostagem em seus lares. A qual pode ser realizada a partir das sobras de comidas sem temperos, para produzir húmus que posteriormente é utilizado como adubo.

Esta iniciativa tem como objetivo reutilizar os resíduos orgânicos que iriam para o lixo e, através de um sistema de autogestão, manter uma horta em casa.

Na sede da COGERSA há também a realização da compostagem, pois há muito resíduo orgânico recolhido pela EMULSA. Através da fermentação aeróbica desses resíduos, cerca de $60 \%$ de restos de vegetais, triturados, e $40 \%$ de fezes de animais, produzem o adubo.

Existem três tipos de resíduos utilizados, tais como: os de origem municipal, vindos da manutenção dos parques e jardins e dos pontos limpos; de origem animal, fezes de animais provenientes de estábulos hípicos; e, resíduos vindos de mercados de compra e venda de gado.

A COGERSA realiza esse trabalho como forma de incentivar os visitantes a realizarem em suas casas a compostagem e, também, para vender o adubo produzido. Também ratifica que essas são algumas ações do governo com o principal objetivo de diminuir resíduos que vão para o aterro sanitário e que podem ser reaproveitados.

\subsection{Resíduos Inorgânicos}

\subsubsection{Pilhas e baterias}

As pilhas e baterias são classificadas como resíduos domiciliares ou resíduos sólidos urbanos, oriundos de eletrodomésticos, telefones celulares, câmeras fotográficas, relógios, etc., surgem do uso habitual e cotidiano em praticamente todas as residências. Esses não podem fazer parte do aterro sanitário porque são classificados como resíduos perigosos.

O Governo do Estado de Astúrias, em março de 1991, iniciou uma campanha para recolher as pilhas e baterias usadas. Desde então, há coletores especializados em vários pontos da cidade para este fim.

Os lugares mais comuns são os painéis publicitários, também conhecidos como mupis, universidades e ruas mais movimentadas. Também nos mercados participantes da campanha pode-se encontrar os recopiladores ou tubo de ECOpilasErro! Fonte de referência não encontrada..

A empresa responsável pelo destino correto desses resíduos no estado é a ECOpila, que, desde 1998, os gerencia e recicla. Após, todos os resíduos são agrupados em centros de 
armazenamentos temporários, os conhecidos SIG's, para posteriormente serem transladados até a planta de classificação e tratamento da ECOpila.

As baterias e pilhas podem ser recicladas, onde os ácidos são neutralizados e, posteriormente, reciclam o plástico e os metais, seguindo a Diretiva 2006/66/CE e o Programa específico do PNIR.

Atualmente há 717 pontos de coleta em Astúrias, dos quais 115 estão em Gijón, além dos quatro pontos limpos. $\mathrm{Na}$

Tabela 1 pode-se observar o aumento na reciclagem destes tipos de resíduos no estado através da comparação entre os anos de 2011, 2012 e 2013 (ECOPILA, 2013).

Tabela 1 - Memorial 2013: coleta de pilhas e baterias em Astúrias.

Fonte: ECOPILA, 2013.

\begin{tabular}{|c|c|c|c|c|c|}
\hline \multirow{2}{*}{ Uso } & \multicolumn{3}{|c|}{ Mercado (kg.) } & Coleta (Kg.) & \multirow{2}{*}{ Índice de coleta (\%) } \\
\cline { 2 - 5 } & $\mathbf{2 0 1 1}$ & $\mathbf{2 0 1 2}$ & $\mathbf{2 0 1 3}$ & $\mathbf{2 0 1 3}$ & $35 \%$ \\
\hline Portátil & 7.114 .232 & 6.613 .855 & 6.240 .288 & 2.322 .947 & \\
\hline
\end{tabular}

\subsubsection{Container amarelo: plástico, alumínio e tetra briks.}

Os containers amarelos recebem três tipos de resíduos: metálicos, plásticos e tetra briks. Todos os resíduos de Astúrias, contidos nesses containers, vão até a sede da COGERSA onde são separados de acordo com suas características.

Os metais, briks e plásticos são prensados em fardos. Os resíduos impróprios, como papel e papelão, ou são transportados para a área desse tipo de reciclagem ou para o aterro sanitário de resíduos não perigosos. Todos os materiais recicláveis são armazenados no lado de fora da planta à espera da carga por um caminhão até a empresa que reciclará.

Os metais também são prensados e posteriormente são enviados para duas empresas responsáveis pela reciclagem em Astúrias, sendo a Ecoembes a mais conhecida e que conta com a associação de mais de 12.000 empresas.

Ecoembes ressalta que em 2013 ultrapassou a meta estabelecida pela União Europeia em reciclagem de alumínio, onde a meta era de reciclar, pelo menos, 50\% de todo o metal produzido, e a mesma reciclou cerca de $84,5 \%$ de todo o metal comercializado.

Atualmente Gijón possui 1.357 containers de resíduos inorgânicos para coleta de recipientes metálicos, plásticos e briks, com peso total de 1.669,1 Kg, para 275.274 habitantes, conforme a 
Tabela 2 (COGERSA, 2014). 
Tabela 2 - Coleta seletiva: embalagens plásticas, metálicas e briks.

Fonte: COGERSA, 2014.

\begin{tabular}{|c|c|c|c|c|c|c|}
\hline \multicolumn{5}{|c|}{ Embalagens: plástico, metais e tetra briks } & Ano 2014 & Ano 2013 \\
\hline $\begin{array}{c}\text { Municípi } \\
\text { o }\end{array}$ & $\begin{array}{c}\text { o total de } \\
\text { containers }\end{array}$ & $\begin{array}{c}\text { Peso } \\
\text { Total (t) }\end{array}$ & $\begin{array}{c}\text { No } \\
\text { habitantes }\end{array}$ & $\begin{array}{c}\text { No hab./ } \\
\text { container }\end{array}$ & $\begin{array}{c}\text { Kg/ } \\
\text { habitante }\end{array}$ & $\begin{array}{c}\text { Kg/ } \\
\text { habitante }\end{array}$ \\
\hline Gijón & 1.357 & $1.669,1$ & 275.274 & 203 & 12,1 & 12,2 \\
\hline
\end{tabular}

\subsubsection{Vidros}

Os vidros podem ser depositados em containers verdes claros desde 1995, quando a cidade começou a coleta seletiva deste material. Existem dois tipos de containers, os de tipo iglu e os subterrâneos, ambos com carga superior, conforme Figura 6.

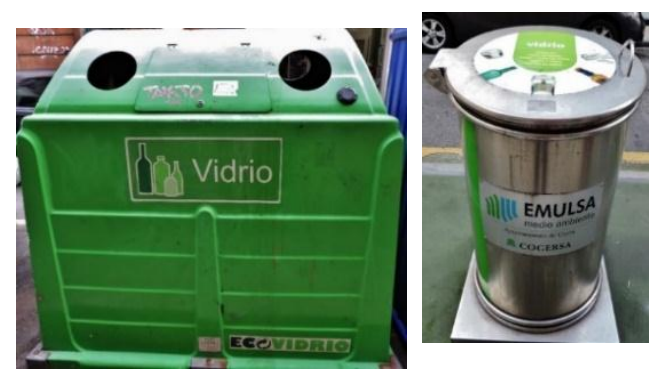

Figura 6 - Container iglu fixo com carga superior - Container subterrâneo com carga superior

Nesses containers podem ser descartadas as garrafas, os potes, copos e taças, jarras, e outros objetos de vidro. Sendo que os vidros de medicamentos só podem ser descartados nos Pontos Limpos. Também não devem ser descartadas as tampas de plástico ou de metal das garrafas neste tipo de container.

Geralmente os vidros já chegam quebrados na sede da COGERSA, o que ajuda na trituração que são submetidos. A Ecovidrio é responsável pela gestão dos vidros depositados nos containers verdes e, o Sistema Nacional de Gestão de Resíduos e Embalagens de Medicamentos A. C. - SIGRE é responsável pela gestão dos medicamentos e suas embalagens.

Atualmente Gijón possui 1.375 containers de resíduos inorgânicos verde claros para coleta de vidros, com peso total de $2.406 \mathrm{Kg}$, para 275.274 habitantes, ou seja, 17,5 $\mathrm{Kg}$ por habitante e 200 habitantes por container, conforme a 
Tabela 3 (COGERSA, 2014). 
Tabela 3 - Memorial 2013: Coleta Seletiva de vidro em Gijón.

Fonte: COGERSA, 2014.

\begin{tabular}{|c|c|c|c|c|c|c|}
\hline \multicolumn{5}{|c|}{ Vidros } & Ano 2014 & Ano 2013 \\
\hline Município & $\begin{array}{c}\text { No total de } \\
\text { containers }\end{array}$ & $\begin{array}{c}\text { Peso } \\
\text { Total (t) }\end{array}$ & $\begin{array}{c}\text { No } \\
\text { habitantes }\end{array}$ & $\begin{array}{c}\text { No hab./ } \\
\text { container }\end{array}$ & $\begin{array}{c}\text { Kg/ } \\
\text { habitantes }\end{array}$ & $\begin{array}{c}\text { Kg/ } \\
\text { habitantes }\end{array}$ \\
\hline Gijón & 1.375 & $2.406,0$ & 275.274 & 200 & 17,5 & 17,5 \\
\hline
\end{tabular}

\subsubsection{Papéis e papelões}

Os papéis e papelões são depositados em containers da cor azul, como os mostrados na Figura 7, que podem ser encontrados ao longo das ruas e praias da cidade.

\section{Erro! Fonte de referência não encontrada.}

Nos containers azuis podem ser descartados os diários, papéis de presente, folhetos publicitários, caixas de papelão, folhas, embalagens de papel, jornal, dentre outros. Não é possível descartar papel e papelão com restos de comida, papéis plastificados e papel toalha usado.

Na sede da COGERSA existe um local para classificação de todo o papel e papelão que chegam dos containers azuis, do comércio e dos grandes produtores de Astúrias. Este local foi inaugurado em 2007 e, de acordo com a COGERSA, tem capacidade de abrigar 42.000 toneladas de resíduos ao ano, por turno de trabalho.

Por fim, obtém-se papel mesclado, papelão, jornais/revistas e os impróprios, onde os três primeiros são prensados e, posteriormente, reciclados, e os impróprios vão para o aterro, como citado anteriormente. Todo o material prensado é armazenado no lado de fora da planta onde são vendidos para os recicladores (COGERSA, 2014).

Atualmente Gijón possui 1.568 containers de resíduos inorgânicos azuis, com total de $3.638 \mathrm{Kg}$, para 275.274 habitantes, ou seja, 26,4 Kg por habitante e 176 habitantes por container, conforme

Tabela 4 .

Tabela 4 - Coleta seletiva de papel/papelão em Gijón.

Fonte: COGERSA, 2014.

\begin{tabular}{|c|c|c|c|c|c|c|}
\hline \multicolumn{5}{|c|}{ Papel / Papelão } & Ano 2014 & Ano 2013 \\
\hline Município & $\begin{array}{c}\text { No total de } \\
\text { containers }\end{array}$ & $\begin{array}{c}\text { Peso } \\
\text { Total } \\
\text { (t) }\end{array}$ & $\begin{array}{c}\text { No } \\
\text { habitantes }\end{array}$ & $\begin{array}{c}\text { No } \\
\text { habitantes/ } \\
\text { container }\end{array}$ & $\begin{array}{c}\text { Kg/ } \\
\text { habitantes }\end{array}$ & $\begin{array}{c}\text { Kg/ } \\
\text { habitantes }\end{array}$ \\
\hline Gijón & 1.568 & $3.638,0$ & 275.274 & 176 & 26,4 & 27,6 \\
\hline
\end{tabular}


Atualmente duas empresas são responsáveis pelo gerenciamento dos papéis e papelões em Astúrias: a Ecoembes e a Recicla Papel.

\subsubsection{Roupas, calçados e complementos}

Cáritas Astúrias e EMULSA impulsionaram o serviço de recolhimento de roupa usada para reutilização e reciclagem, através de 55 containers, com capacidade de 2.500 litros, distribuídos por vários pontos da cidade, conforme Figura 7.

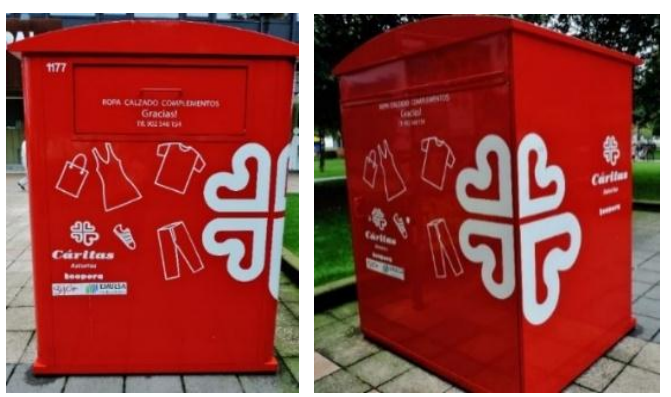

Figura 7 - Containers da Cáritas para coleta de roupas e calçados: Praça Fábrica de Gás.

Cáritas é a responsável pela seleção, classificação e tratamento das roupas, assim como o desenvolvimento de um projeto de comercialização, para criar, pelo menos, quinze postos de trabalho, em um prazo de três anos.

As roupas que não podem ser reutilizadas por outras pessoas, servem de matéria prima, trapo de limpeza industrial, tapeçaria, etc. Este projeto tem como o objetivo ambiental de fortalecer a recuperação seletiva e de reciclagem dos tecidos têxteis que acabam no lixo sem utilidade e, social, com o objetivo de criar emprego estável e disponibilizar acesso às roupas para as pessoas mais necessitadas.

Durante o primeiro semestre de 2014 foram coletadas em Gijón cerca de 100.769 kg de roupa para a reutilização ou reciclagem. Este número significa multiplicar quase quatro vezes a arrecadação completa em 2013, que chegou a $26.410 \mathrm{~kg}$. O possível aumento da doação de roupas pode ser por causa crescente número de containers distribuídos na cidade (EMULSA, 2014).

Os containers são facilmente identificáveis, têm fácil acesso e estão localizadas nas praças, proporcionando uma coleta de 24 horas.

Atualmente Cáritas possui 95 containers vermelhos distribuídos em oito municípios de Astúrias, com a coleta mensal de aproximadamente 70 toneladas de roupa.

\subsection{Resíduos Inorgânicos Perigosos}


Os Pontos Limpos são instalações onde a população deposita resíduos especiais, aquele que não podem ser descartados nos containers citados anteriormente, pois de acordo com as características e composição, devem receber tratamento especial e não fazer parte do aterro sanitário da cidade.

Além de permitir a reciclagem e evitar problema no tratamento de outros resíduos, esses são mantidos sob responsabilidade, vigilância e limpeza da prefeitura.

No interior dos Pontos Limpos existem containers identificados para cada tipo de resíduos, indicando à população onde depositar seus resíduos especiais, tais como: pilha, baterias, lâmpadas fluorescentes, óleo de motor, escombros, pneus, etc.

Cada resíduo é encaminhado para a reciclagem, através da COGERSA. Por exemplo: o óleo de motor é analisado, tratado e utilizado como combustível; o azeite de cozinha usado é utilizado para fabricação de biodiesel; as roupas são encaminhadas à CARITAS; os restos de vegetais são para produção de composto na COGERSA; móveis e volumosos são entregues em empresas que reciclam e reutilizam, como a Asociación RETO e a Emaus Gijón (COGERSA, 2014).

O aterro de resíduos perigosos foi construído em 1991 na sede da COGERSA, e começou a receber os resíduos no seguinte ano. Passou por várias fases de melhoramento até cumprir os requisitos do Decreto Real 1481/2001. A capacidade total é de $600.000 \mathrm{~m}^{3}$ e pode ser dividido de três formas: estrutura, proteção das águas superficiais e drenagem dos lixiviados.

\section{Conclusão}

O principal objetivo desta pesquisa foi expor a importância da Educação Ambiental como ferramenta eficaz de mudança, tendo em vista que para se ter qualidade de vida, é preciso primeiro conservar e preservar o meio ambiente. A este fato se adiciona a iniciativa do poder público, que pode incentivar muitos avanços nessa área juntamente com a população local.

Observa-se a preocupação do poder público em cumprir as leis e diretivas da União Europeia e torná-las acessíveis à população local.

Através disso, verificou-se que os resíduos recicláveis diminuíram no aterro sanitário, onde os gijoneses produziram menos resíduos e reciclaram mais.

Em virtude dos fatos mencionados no presente estudo, conclui-se que o sistema de gestão dos resíduos sólidos e a metodologia de ensino da educação ambiental utilizada em Gijón/Espanha é um modelo e exemplo para outras cidades e países.

Os resultados que demonstram a redução sucessiva dos resíduos descartados reforçam que iniciativas de educação ambiental são úteis e eficazes no desenvolvimento sustentável.

\section{Agradecimento}


Ao Prof. Dr. Catedrático do Depto. de Ingeniería Química da UNIOVI, Gijón/Espanha, Hermínio Sastre Andrés, pelo apoio, auxílio e orientação durante as minhas pesquisas realizadas na Espanha.

\section{Referências}

ASTURGALÍCIA NOTÍCIAS. [Internet] Cogersa adjudica obras, servicios y suministros por 1,8 millones; 16 de agosto de 2008 [cited 27 set. 2014]. Disponível a partir de: http://asturgalicia.net/tag/cogersa/.

CONSÓRCIO PARA A GESTÃO DE RESÍDUOS SÓLIDOS DE ASTÚRIAS - COGERSA. [Internet] ACERCA DE COGERSA; [cited 15 set. 2014]. Disponível a partir de: http://www.cogersa.com/metaspace/portal/14498/18718?vpg=2.

. [Internet] Campaña de Compostaje Doméstico 2014; [cited 15 set. 2014]. Disponível a partir de: http://www.cogersa.com/metaspace/portal/14498/50057.

_. [Internet] Captación de biogás; [cited 15 out. 2014]. Disponível a partir de: http://www.cogersa.es/metaspace/portal/14498/19174.

_. [Internet] Captación y aprovechamiento de biogás: Memoria anual 2013, pág. 47; [cited 15 out. 2014]. Disponível a partir de: http://www.cogersa.es/metaspace/portal/14498/49005informes?pms=1,48765,48688003, view,normal,0.

. [Internet] Fototeca de Fines de Semana Verdes; [cited 14 set. 2014]. Disponível a partir de: http://www.cogersa.es/metaspace/portal/14498/49531.

_. [Internet] Punto Limpio Movil; [cited 30 set. 2014]. Disponível a partir de: http://www.cogersa.es/metaspace/portal/14498/19258.

_. [Internet] Planta de selección de envases ligeiros; [cited 05 out. 2014]. Disponível a partir de: http://www.cogersa.es/metaspace/portal/14498/19175.

. [Internet] Planta de selección de papel y cartón; [cited 19 out. 2014]. Disponível a partir de: http://www.cogersa.es/metaspace/portal/14498/19179.

. [Internet] Residuos eliminados en el Vertedero Central de Asturias. Memoria anual 2013, pág. 14; [cited 15 out. 2014]. Disponível a partir de: 
http://www.cogersa.es/metaspace/portal/14498/18720-informes-anuales-degestion?pms=1,48335,50251004, view,normal,0

. [Internet] Vertedero de Residuos Peligrosos; [cited 22 out. 2014]. Disponível a partir de: http://www.cogersa.es/metaspace/portal/14498/19204.

ECOEMBES. [Internet] Informa anual: 2013; [cited 21 out. 2014]. Disponível a partir de: http://www.ecoembes.com/es/ciudadanos/ecoembes/publicaciones/informe-anual-2013.

ECOpilas. [Internet] Legislación. Directiva 2006/66/CE del Parlamento Europeo y del Consejo de 6 de septembre de 2006. Real Decreto 106/2008 de Pilas y Baterías usadas; [cited 18 set. 2014]. Disponível a partir de: http://www.ecopilas.es/objetivos-y-procesos/legislacion/.

_. [Internet] Memorial 2013; [cited 29 out. 2014]. Disponível a partir de: http://www.ecopilas.es/sala-de-prensa/catalogos-y-memorias/.

EMULSA. [Internet] 24 operarios de EMULSA se suman a 30 Dias em Bici Gijón; [cited 06 set. 2014]. Disponível a partir de: https://cuidadoambiental.gijon.es/noticias/show/22827emulsa-se-suma-a-30-dias-en-bici-gijon.

. [Internet] Campaña de Sensibilización Medioambiental Ciudadana 2012/2013 y presentación de la acción “¿Sabias que...?”; 20 de agosto de 2013; [cited 02 set. 2014]. Disponível a partir de: http://cuidadoambiental.gijon.es/noticias/show/20710-campana-desensibilizacion-medioambiental-ciudadana-2012-2013-y-presentacion-de-la-accion-sabiasque.

_. [Internet] Cáritas Asturias Y EMULSA impulsionan un servicio de recogida de ropa usada para su reutilización y reciclaje; 27 de maio de 2014; [cited 04 set. 2014]. Disponível a partir de: http://cuidadoambiental.gijon.es/noticias/show/23637-caritas-asturias-y-emulsaimpulsan-un-servicio-de-recogida-de-ropa-usada-para-su-reutilizacion-y-reciclaje

_. [Internet] Concurso de Arboles de Navidad Reciclados em Colegios de Gijón; 19 de setembro de 2013; [cited 01 set. 2014]. Disponível a partir de: https://www.facebook.com/media/set/?set=a.566876723392225.1073741831.109196332493602\& type $=3$.

_. [Internet] EMULSA abre la inscripción em el concurso artístico “Otoño del reciclaje"; 01 de setembro de 2014; [cited 02 set. 2014]. Disponível a partir de: http://cuidadoambiental.gijon.es/noticias/show/24556-emulsa-abre-la-inscripcion-en-elconcurso-artistico-otono-del-reciclaje 
_. [Internet] Contenedores accesibles; 28 de março de 2011 [cited 04 set. 2014]. Disponível a partir de: http://www.gijon.es/noticias/show/11332-contenedores-accesibles

.[Internet] Gijón capital del reciclagem; 16 de maio de 2013; [cited 11 set. 2014].

Disponível a partir de:

https://www.facebook.com/media/set/?set=a.466081340138431.1073741826.109196332493602\& type $=1$.

_. [Internet] Los gijoneses reciclaron 23.060 litros de aceite usado de cocina; 10 de setembro de 2014; [cited 14 set. 2014]. Disponível a partir de:

https://cuidadoambiental.gijon.es/noticias/show/24661-los-gijoneses-reciclaron-23-060-litrosde-aceite-usado-de-cocina

.[Internet] Taller para niños/as de Reutilización de Ropa; 05 de abril de 2013; [cited 05 set. 2014]. Disponível a partir de:

https://www.facebook.com/media/set/?set=a.448390678574164.1073741825.109196332493602\& type $=3$.

EUROPA PRESS. [Internet] El punto limpio móvil de Cogersa hace recogida separada de resíduos tóxicos y electrodomésticos em 19 concejos rurales; 14 de junho de 2014 ; [cited 03 set. 2014]. Disponível a partir de: http://www.europapress.es/asturias/noticia-punto-limpiomovil-cogersa-hace-recogida-separada-residuos-toxicos-electrodomesticos-19-concejosrurales-20140614131137.html

LORENZO, M. [Internet] Impactos Ambientais; 10 de outubro de 2010; [cited 18 set. 2014]. Disponível a partir de: http://marianaplorenzo.com/2010/10/10/o-lado-positivo-da-pilha\%E2\%80\%93-parte-iii-impactos-ambientais-2/

NOTÍCIAS MEIO AMBIENTE. [Internet] Directiva europeia de 18 de março, 1991; [cited 18 set. 2014]. Disponível a partir de: http://www.actu-

environnement.com/ae/reglementation/directive_europeenne_du_18_03_1991_91_157_cee.ph p4.

PATELLI, S. [Internet] Projeto Educação Ambiental; [cited 24 ago. 2014]. Disponível a partir de: http://suelipatelli.blogspot.com.es/p/projeto-de-educacao-ambiental.html.

PESQUEIRA, PREFEITURA MUNICIPAL. [Internet] A era da coleta seletiva na cidade de Pesqueira; [cited 02 nov. 2014]. Disponível a partir de: http://www.pesqueira.pe.gov.br/. 
SERRANO, M. L. [Internet] Incineradora COGERSA estará lista; 13 de março de 2014; [cited 05 out.2014]. Disponível a partir de: http://www.lne.es/asturias/2014/03/13/incineradoracogersa-estara-lista-2020/1555974.html. 